\title{
Out of Nature: Why Drugs from Plants Matter to the Future of Humanity
}

\author{
Kara Rogers. 2012. The University of Arizona Press, Tucson. Pp. 216. \$19.95 (paper). ISBN 978-0-8165-2969-8.
}

Reviewed by Kris Gremillion

Reviewer address: 174 West 18th Avenue, Department of Anthropology, 4034 Smith Laboratory, The Ohio State University, Columbus, $\mathrm{OH}$ 43210. gremillion.1@osu.edu

In this book, Kara Rogers makes an impassioned plea for a renewed awareness of 'nature' in the industrialized world. Only by connecting with the living world will people develop the kind of deep appreciation for other living things that allows conservation efforts to succeed. Rogers is particularly concerned about the erosion of biodiversity and traditional plant knowledge because of the key role they can play in medicine on a global scale. She builds her argument by carefully explaining the basics of botany and plantbased ethnomedicine and describing the debt owed to traditional plant knowledge by Western medicine. Rogers argues that there is an innate human propensity to connect with the natural world, illustrating this point with a brief history of European plant collecting. She goes on to detail the benefits of maintaining diversity in both wild and cultivated plant populations, and discusses the ethical and practical issues involved in biodiversity conservation and prospecting. Rogers concludes by revisiting the importance of the innate human attraction to the natural world in fueling conservation efforts.

The first chapter, on plants and medicine, discusses the replacement of natural phytochemicals with synthetic ones. Large-scale commercialization has reduced drug diversity, whereas traditional medicine maintains the connections between humans and nature. In Chapter 2, Rogers elaborates on the theme of the interconnectedness of humans and the plant world and how it is reflected in early botany and herbalism. Chapter 3 is something of a hodgepodge- it begins with a discussion of the concept of biophilia as an innate human desire to connect with nature. This desire emerges naturally from the broader network of interactions between species. Biophilia drove early Western exploration of the plant world and the drug discoveries that resulted from it. In elaborating on this phenomenon, Rogers recounts many of the important expeditions of this era-from ancient Egypt to the Tradescants, Sir Joseph Banks, and the early-twentieth century plant collecting ventures in the Far East. Unfortunately, this passion for discovering the wonders of nature waned, and with it the search for plant medicines. Rogers then leaps back in time to the origins of medicine and reiterates the importance of a felt connection with nature to conservation of biodiversity. There is much useful information in this chapter, particularly about the history of botanical exploration, but it is not always evident exactly how the different threads of discussion are related to each other and to the concluding plea for awareness of nature.

Chapter 4 is a history of gardens and other natural places, such as natural parks, and the role they play in maintaining the human connection to the natural world and thus to preservation of biodiversity. Visitors to botanical gardens and other natural areas cultivate an appreciation for nature that Rogers believes is a key component of successful conservation on a global scale. The conclusion to this chapter introduces the topic of Chapter 5, which is extinction. Here Rogers discusses a series of specific ongoing conservation problems, including the overharvesting of medicinal plants such as gingko and ginseng in China, the effects of deforestation on tropical ecosystems, and the disappearance of endemics from the island of St. Helena. Chapter 6 is about modern drug discovery and the contributions of plants to contemporary medicine. It presents many of the cases that are frequently discussed in textbooks, such as the extraction of anti-cancer compounds from the Madagascar periwinkle. Rogers' thesis is that plants 
remain an important source of healing substances even though many compounds can be synthesized in the laboratory, a fact that highlights the urgency of conservation measures. Chapter 7 turns to the challenges and potential of collaboration between custodians of traditional botanical knowledge and those who seek to develop plant-derived natural products. Bioprospecting efforts rely for their success on respectful collaboration with these knowledgeholders and active efforts to keep harvesting at a sustainable level. The final chapter considers plant conservation on a global scale, reiterating the importance of personal experience of nature on the part of the wider public.

The book is rich in information and clearly written and well-researched, and Rogers' writing style is smooth and professional. She effectively communicates her plea for conservation and ethically informed drug development based on traditional botanical knowledge. Rogers enlivens her descriptions of history, plant discovery, and policy with detailed examples-for example, the development of malaria drugs from wormwoods and the threat of overharvesting of ginseng. Though necessarily selective, these narratives engage the reader and help to illustrate broader patterns. The book overall is logically organized, although some of the chapters (for example, Chapter 3) are so rich in detail that it is hard to discern a unifying theme.

For the advanced student and professional, Rogers is preaching to the choir when it comes to the exhortation to promote conservation and respect nature. However, much of the information presented will be eye-opening for students in an introductory course in economic botany or ethnopharmacology. Dedicated lay readers will also find the book highly informative. Out of Nature will enlighten many and should raise awareness of these important issues. Still, it's not the book itself but the author's advice to get out and experience the natural world directly that is likely to arouse a passion for biodiversity conservation 